\title{
Atypical Auditory Event-Related Potentials in Preterm Infants during the First Year of Life: A Possible Sign of Cognitive Dysfunction?
}

\author{
VINETA FELLMAN, ELENA KUSHNERENKO, KAIJA MIKKOLA, RITA CEPONIENE, \\ JAANA LEIPÄLÄ, AND RISTO NÄÄTÄNEN \\ Hospital for Children and Adolescents [V.F., K.M., J.L.], Helsinki University Central Hospital, Helsinki, \\ Finland, 00029 Helsinki, Finland; Cognitive Brain Research Unit [E.K., R.C., R.N.], University of \\ Helsinki, 00014 Helsinki, Finland; and Department of Pediatrics [V.F.], Lund University, 22185 \\ Lund, Sweden
}

\begin{abstract}
ABST
We assessed auditory event-related potentials in small-for-
gestational-age (SGA; $850 \pm 258 \mathrm{~g}, 28.9 \pm 3.3$ gestational wk;
$n=15)$ and appropriate for gestational age (AGA; $1014 \pm$
$231 \mathrm{~g}, 26.9 \pm 1.9$ gestational wk; $n=20)$ preterm infants and
healthy term infants $(n=22)$. An oddball paradigm was used
with a harmonic tone of $500-\mathrm{Hz}$ frequency as the standard and of
750 -Hz frequency as the deviant stimulus. The preterm infants
were studied at 40 gestational wk and at 6 and 12 mo of corrected
age, and the control subjects were studied at $2-4 \mathrm{~d}$ and at 3,6 ,
9,12, and 15 mo of age. The peaks of interest were the main
positive peak (P350), the negative peaks at 250 ms (N250) and
650 ms (Nc), and the mismatch negativity at 200 ms (MMN). At
term, the P350 in the preterm infants was similar to that of the
newborn control subjects. In response to the deviant, the Nc was
smaller in the SGA than in the AGA $(P<0.02)$ and control $(P$
$<0.005)$ infants. The N250 amplitude was also lower in the
SGA infants. At 12 mo, the MMN was observed in the control
\end{abstract}
but not in the preterm infants, whose broad difference positivity correlated with the Bayley developmental index. The decreased $\mathrm{Nc}$ and N250 peaks in the SGA infants may suggest an increased risk for cognitive dysfunction. The broad difference positivity at $1 \mathrm{y}$ of age may indicate atypical cortical auditory processing. Whether cognitive dysfunction can be predicted by these findings needs to be assessed in a study with extended follow-up. (Pediatr Res 56: 291-297, 2004)

Abbreviations
AGA, appropriate for gestational age
ERP, event-related potential
MDI, Mental Developmental Index
MMN, mismatch negativity
Nc, negative component
SGA, small for gestational age
VLBWI, very low birth weight infants

The survival of very low birth weight infants (VLBWI; birth weight $<1500 \mathrm{~g}$ ) has significantly improved during the last two decades, especially of those with a gestational age $<28$ wk $(1,2)$. The impairment rate has remained similar or only slightly decreased, thus resulting in an increased absolute number of infants with neurodevelopmental abnormalities $(3,4)$. In very preterm infants, the rate of severe handicap, such as cerebral palsy, deafness, blindness, and mental retardation, has in recent studies varied from 15 to $25 \%(1,3)$. Cognitive dysfunction and learning disabilities are even more common.

Received August 26, 2003; accepted February 9, 2004.

Correspondence: Vineta Fellman, M.D., Ph.D., Hospital for Children and Adolescents, Helsinki University Central Hospital, P.O. Box 281, 00029 Helsinki, Finland; e-mail: vineta.fellman@helsinki.fi

The study was supported by grants from Helsinki University Central Hospital, The Medical Society of Finland (Finska Läkaresällskapet), and the Academy of Finland, project number 79820 .

DOI: 10.1203/01.PDR.0000132750.97066.B9
In a large VLBWI birth cohort study in the Netherlands, at the age of $9 \mathrm{y}, 56 \%$ of children in mainstream education needed special assistance at school or were below the age-appropriate level (5). Similar results have been reported from other countries (6).

Several perinatal risk factors have been associated with poor school performance, such as low birth weight, intraventricular hemorrhage, and need for assisted ventilation (7). Intrauterine growth restriction in preterm infants is associated with increased morbidity, both in the neonatal period and later on; the risk for neurosensory abnormalities is increased compared with appropriately grown preterm infants (8). In a previous study, (9) we showed that growth-retarded VLBWI born in the mid1980s had a poorer neuropsychological performance at $7 \mathrm{y}$ of age than appropriately grown control children.

Although both perinatal risk factors and abnormal neurologic signs early in infancy may be associated with later cognitive disabilities, predicting the risk of impaired cognitive 
development has not been possible because of the lack of a method with sufficient specificity and sensitivity. The most rapid motor, cognitive, and perceptual development occurs during the first and second years of life. Thus, a method that measures these abilities early in life would provide a new tool to identify individuals with an increased risk of later cognitive problems.

Electrical signals related to some external or internal events [event-related potentials (ERPs)] provide real-time indices of neural information processing (10). The ability of the developing brain to discriminate auditory information is present from the second trimester of fetal life, and this capacity can be measured objectively and noninvasively with ERPs from birth (11). The ERP curve is composed of a number of peaks and troughs labeled according to their polarity and latency. Longlatency ERPs are more variable and are elicited less reliably near their threshold than widely used short-latency auditory brain responses; however, they offer a unique opportunity to evaluate higher-order cortical auditory processes (12). The main positive peaks at $\sim 150$ and $350 \mathrm{~ms}$ (P150 and P350, respectively) and the negative peak between them (N250) are identifiable in healthy full-term newborn infants at birth (13). The mismatch negativity (MMN) is a negative component of the ERP at $\sim 200 \mathrm{~ms}$, which is elicited when a discernible change occurs in a sequence of repetitive homogeneous stimuli and reflects the brain's automatic change-detection response (14). In contrast, the late negative component $(\mathrm{Nc}$; peaking at $550-650 \mathrm{~ms}$ ) is thought to reflect attentional cognitive processes. It is elicited in response to a change in a stream of either salient identical or novel attention-evoking sounds (15). Furthermore, the positive P3a peaking at $250-350 \mathrm{~ms}$, which in adults is considered a correlate of auditory orienting to deviant stimuli, has been identified in newborns (16).

We hypothesized that auditory ERPs can be used as an early indicator of impaired cognitive development in preterm infants. The aim of the present study was to test this hypothesis by assessing the development of the auditory ERPs, especially of the MMN and Nc, during infancy in preterm infants with a high risk for later cognitive disabilities and comparing them with healthy term infants. In addition, we evaluated whether ERP abnormalities during the neonatal period could predict an adverse outcome at $2 \mathrm{y}$ of age.

\section{METHODS}

All infants were born in the Department of Obstetrics and Gynecology, Helsinki University Central Hospital, and recruited to the study postnatally after informed written parental consent was obtained for each infant. The study project was approved by the ethics committee of the Hospital for Children and Adolescents, Helsinki University Central Hospital, and in addition, regarding the control infants, by the ethics committee of the Department of Obstetrics and Gynecology.

Study subjects. Preterm infants who had a birth weight $<1500 \mathrm{~g}$ and were treated in the neonatal intensive care unit of the Hospital for Children and Adolescents, Helsinki University Central Hospital, were enrolled in the small-for-gestational-age (SGA) group when the birth weight was $<-2 \mathrm{SD}$ for gestation and in the appropriate-for-gestational-age (AGA) group when it was within the $\pm 1 \mathrm{SD}$ range. Infants with acute birth asphyxia (umbilical artery $\mathrm{pH}<7.05$ ), chromosomal abnormalities, and major congenital heart disease were excluded from the study. Gestational age was determined by fetal ultrasonography. The routine prenatal follow-up included weight estimation by ultrasonographic assessments of abdominal circumference and early second-trimester fetal biparietal diameter measurement. The clinical characteristics are presented in Table 1 . The infants were treated according to the routine clinical guidelines of the neonatal intensive care unit. ERPs were recorded at the corrected age of $40( \pm 2)$ gestational weeks and later at the corrected age of 6 and $12 \mathrm{mo}( \pm 2 \mathrm{wk})$. At the age of $24 \mathrm{mo}$, the infants underwent a neurologic and developmental assessment (Bayley Scales of Infant Development) at the Hospital for Children and Adolescents. Fourteen infants were

Table 1.Clinical neonatal characteristics of SGA and AGA preterm infants and of healthy term control infants

\begin{tabular}{|c|c|c|c|}
\hline & SGA $(N=15)$ & $\operatorname{AGA}(N=20)$ & Control $(N=22)$ \\
\hline Birth weight $(\mathrm{g})$ & $\begin{array}{l}850 \pm 258^{*} \\
(510-1380)\end{array}$ & $\begin{array}{l}1019 \pm 233 \\
(580-1485)\end{array}$ & $\begin{array}{c}3774 \pm 404 \\
(3140-4580)\end{array}$ \\
\hline Gestational age (wk) & $\begin{array}{r}29.0 \pm 3.3^{*} \\
(25.1-37.4)\end{array}$ & $\begin{array}{l}26.9 \pm 1.9 \\
(24.0-30.3)\end{array}$ & $\begin{array}{r}40.6 \pm 0.8 \\
(39-41,9)\end{array}$ \\
\hline Cord arterial $\mathrm{pH}$ & $\begin{array}{c}7.25 \pm 0.09 * \\
(7.05-7.39)\end{array}$ & $\begin{array}{l}7.32 \pm 0.08 \\
(7.09-7.42)\end{array}$ & $\begin{array}{l}7.26 \pm 0.07 \\
(7.14-7.44)\end{array}$ \\
\hline Apgar score, $1 \mathrm{~min}$ & $\begin{array}{c}5.5 \pm 2.3 \\
(1-9)\end{array}$ & $\begin{array}{c}6.1 \pm 1.6 \\
(3-8)\end{array}$ & $\begin{array}{l}8.9 \pm 0.43 \\
(8-10)\end{array}$ \\
\hline Vaginal delivery $[n(\%)]$ & $3(20)^{*}$ & $11(55)$ & $18(82)$ \\
\hline Male sex $[n(\%)]$ & $8(53)$ & $10(50)$ & $14(64)$ \\
\hline Antenatal steroids $[n(\%)]$ & $13(80)$ & $18(90)$ & $0(0)$ \\
\hline Postnatal dexamethasone $[n(\%)]$ & $4(27)$ & $5(25)$ & $0(0)$ \\
\hline Maternal preeclampsia $[n(\%)]$ & $11(73)$ & $1(5)$ & $0(0)$ \\
\hline Respiratory distress syndrome $[n(\%)]$ & $11(73)$ & $15(75)$ & $0(0)$ \\
\hline Patent ductus arteriosus $[n(\%)]$ & $10(67)$ & $14(70)$ & $0(0)$ \\
\hline Mechanical ventilation (d) & $11.4 \pm 10.7$ & $11.4 \pm 12.8$ & $0(0)$ \\
\hline Intraventricular hemorrhage, grade II-IV $[n(\%)]$ & $2(13)$ & $4(20 \%)$ & Not examined \\
\hline Retinopathy of prematurity $[n(\%)]$ & $1 / 15(7)$ & $1 / 20(5)$ & Not examined \\
\hline
\end{tabular}

Data are mean $\pm \mathrm{SD}$ (range) or $n(\%)$.

* Significant difference compared with AGA group $(P<0.05)$. 
followed up at their local hospital and were therefore not assessed with the Bayley scale.

Full-term control infants were recruited from the postdelivery wards, sex-matched with the preterm infants, and first examined at the age of 2-4 d (Table 1). They were later investigated at $3,6,9,12$, and 15 mo of age to enable age-matched comparison with the preterm infants at both postconceptional and postnatal age. All infants were considered healthy in the neonatal period by a neonatologist and developed normally during the follow-up period. The families did not have a history of hearing, language, or reading pathology.

Experimental conditions. Before the ERP recording, all infants passed a hearing screening test (ILO88 Dpi system; Otodynamics Ltd, Hatfield, UK) using evoked otoacoustic emissions, i.e. cochlear responses to test sounds. Newborns and 3- and 6-mo-old infants were studied in a silent room in the Hospital for Children and Adolescents. Newborn infants were lying in an infant's cot, with two loudspeakers located at a distance of $20 \mathrm{~cm}$ from each ear. Three- and 6-mo-old infants were tested while sitting in a safety seat or on their parent's lap. Nine, 12-, and 15-mo-old infants were studied while sitting on their parent's lap and watching a silent cartoon in a soundproof and electromagnetically shielded chamber at the Department of Psychology, University of Helsinki. The experiments lasted for $\sim 1-1.5 \mathrm{~h}$.

In total, 13 disposable electrodes were used, 8 of which were attached to standard scalp sites according to the International 10-20 system: F3, F4, C3, C4, P3, P4, T3, and T4. Two electro-oculogram electrodes were placed vertically and horizontally to the right eye. One electrode was placed on the left mastoid, one on the right mastoid, and one, the ground electrode, on the forehead. All electrodes were referenced to the right mastoid. The EEG was recorded (bandpass $0.1-30 \mathrm{~Hz}$, sampling rate $250 \mathrm{~Hz}$ ) using the NeuroScan 3.0 acquisition software. The data were off-line re-referenced to the average of the left and right mastoids, filtered at $1.0-15 \mathrm{~Hz}$, and baseline corrected with respect to the mean 100-ms prestimulus voltage. The first three epochs of each block and those with an absolute EEG voltage in any channel exceeding \pm 150 microvolts were discarded from averaging.

A "frequency oddball paradigm" (Fig. 1) was used, which in a previous study (17) elicited the MMN response in $85 \%$ of the newborn infants. A $100-\mathrm{ms}$ three-partial harmonic tone of $500-\mathrm{Hz}$ fundamental frequency (i.e. 500,1000 , and $1500 \mathrm{~Hz}$ sinusoidals) was used as the standard tone, and a harmonic tone of $750-\mathrm{Hz}$ fundamental frequency was used as the deviant. The standards were presented with an 800-ms stimulus onset asynchrony (from onset to onset) occurring at a probability of $85 \%$,

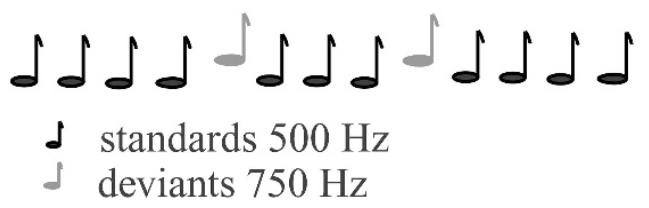

Figure 1. Cartoon of the frequency oddball paradigm, showing the standard 100 -ms three-partial harmonic tone of $500-\mathrm{Hz}$ fundamental frequency and the random deviant tone. and the deviant tone was randomly presented at a probability of $15 \%$. All sounds had an intensity of $70 \mathrm{~dB}$ sound-pressure level at the infant's head.

Mean ERP amplitudes were calculated over the data points of the consecutive $100-\mathrm{ms}$ periods starting at $50 \mathrm{~ms}$ from the stimulus onset (i.e. over the 50 - to $150-\mathrm{ms}, 150$ - to $250-\mathrm{ms}$, 250 - to $350-\mathrm{ms}, 350-$ to $450-\mathrm{ms}, 450-$ to $550-\mathrm{ms}$, and $550-$ to 650 -ms periods). This was done separately for the responses to the standard tones that preceded the deviants and those to the deviant tones. Because the main focus was investigating mismatch response, which does not occur earlier than $80 \mathrm{~ms}$ from stimulus onset, we disregarded any activity before $50 \mathrm{~ms}$.

A mean voltage difference representing the brain's response to change was calculated for each 100 -ms period by subtracting the corresponding standard amplitude from the deviant ERP amplitude. Only significant results are reported.

Statistics. The statistical analyses of the data were performed with the appropriate designs of the ANOVA, and post hoc tests were applied to determine the sources of the significant ANOVA effects. Data from all electrodes were included in the ANOVAs. The clinical data were tested with the $t$ test or $\chi^{2}$. Greenhouse-Geisser adjustment was performed when applicable (corrected $P$ values are reported). $P<0.05$ was considered significant.

\section{RESULTS}

At the age of 24 mo, 12 (80\%) SGA infants and $13(70 \%)$ AGA infants were considered neurologically normal. Cerebral palsy was diagnosed in three (20\%) SGA infants and in three (15\%) AGA infants, one of whom had severe hemiplegia as a result of intrauterine ischemic insults. Speech development was delayed in two SGA and in three AGA infants. The mean Bayley Mental Developmental Index (MDI) was $96 \pm 13$ (range, 76-114; $n=10$ ) in the SGA and $99 \pm 13$ (range, $78-120 ; n=11)$ in the AGA infants.

The ERP experiments were performed at term in $8 \mathrm{SGA}$ and 14 AGA infants, at the age of 6 mo in 10 SGA and 12 AGA infants, and at the age of 12 mo in 9 SGA and 12 AGA infants. Nine infants were recorded three times, 12 twice, and 14 once.

ERPS at term. In the preterm infants at the age of 40 gestational wk (Fig. 2), the main positive peak (P150 + P350) of the ERP in response to the standard tone measured as the mean amplitude over the 150 - to $250-\mathrm{ms}$ and 250 - to $350-\mathrm{ms}$ periods was similar to that of the 2- to 4-d-old full-term infants, i.e. control infants of the same postconceptional age. Although there were no significant group differences, in both preterm groups, the later part of the fused P150 + P350 peak looked ill-defined. When compared with the corresponding peak of the control infants at the same postnatal age (3 mo; Fig. 2), the P150 + P350 peak was smaller in amplitude in both preterm infant groups $[F 3,38)=15.37 ; P<0.0001$ over the 150 - to 250 -ms period; $F(3,38)=11.44 ; P<0.0001$; over the 250 - to 350 -ms period)].

In the 250- to 350-ms period, the ERP response (the P350) to the deviant stimuli was similar in preterm and control newborn infants (i.e. same postconceptional age) but significantly smaller in preterm infants than in the 3-mo-old control 


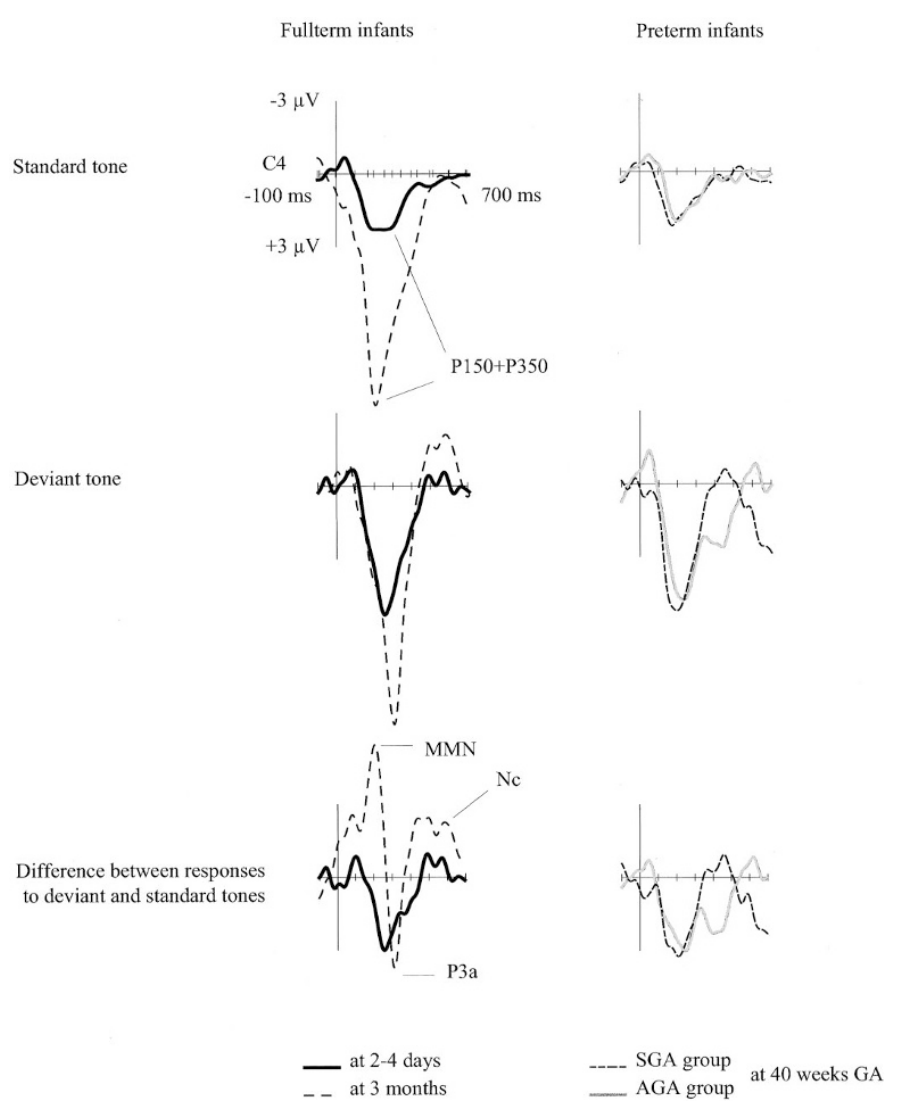

Figure 2. Auditory ERPs to the standard, deviant, and the difference wave between the deviant and standard tone elicited in control infants at the age of $2-4 \mathrm{~d}$ and $3 \mathrm{mo}$ and in SGA and AGA infants at 40 gestational wk of age. The $\mathrm{C} 4$ electrode was chosen because there was no significant difference between the right and left frontal and central electrodes. The $y$ axis indicates the magnitude of the response (identical scales in all panels from -3 above 0 -line to $+3 \mu \mathrm{V}$ below it); the $x$ axis indicates the response time in ms, when the stimulus is given during the time period from -100 to $0 \mathrm{~ms}$. The ERPs to the standard and deviant tone are more positive in the control infants, and the MMN, i.e. the indicator of change detection, is larger in amplitude more negative at 3 mo of age than at term. In both preterm infant groups, the sensory responses are similar to those of the control infants at term, i.e. the same postconceptional age, but the MMN is hardly elicited. The P3a and Nc are indicated (see text).

infants (i.e. infants of the same postnatal age; $F(3,38)=3.37$; $P<0.0284)$. In both preterm groups, the P150 $(150-250 \mathrm{~ms})$ was similar in amplitude to that of the control infants.

The difference between the ERP to the standard tone and that to the deviant tone was analyzed for the 50 - to $150-\mathrm{ms}, 150$ - to $250-\mathrm{ms}$, and 250 - to 350 -ms periods, according to the latency of the change-detection responses in infants (the MMN and P3a) (16). In the newborn control infants, a significant difference between these ERPs was found over the $50-$ to $150-\mathrm{ms}$ period $[F(1,9)=18.73 ; P<0.0019]$ and in the 3-mo-old controls over the 150 - to 250 -ms period $[F(1,9)=5.50 ; P<$ $0.0436]$, with the response to the deviant being significantly less positive than the response to the standard, this negative difference representing the MMN. In the 250- to $350-\mathrm{ms}$ period, a significant difference was observed in the newborn control subjects between the deviant and the standard ERPs $[F(1,9)=6.18 ; P<0.0346]$, with the response to the deviant being more positive than that to the standard. This positive difference corresponded to the positive auditory orienting response, the P3a (Fig. 2).

In the preterm infants at the age of 40 gestational weeks, the only significant difference between the responses to the deviant and standard tones was found in the AGA group over the 150to 250 -ms period $[F(1,13)=4.88 ; P<0.0457]$, with the response to the deviant being more positive than that to the standard. No significant differences were obtained in the SGA group. Furthermore, in response to the deviant stimulus, the late $\mathrm{Nc}$ (measured as the mean amplitude over $550-650 \mathrm{~ms}$ ) was of a lower amplitude in the SGA infants than that in both the AGA and control infants $[F(3,38)=3.32 ; P<0.0298$; Fig. 2].

ERPs at 6 mo of age corrected for prematurity. In the full-term control infants, the precursor of the N250 peak, always elicited in children by repetitive standard stimuli, (13) appeared between 6 and 9 mo of age (Fig. 3). A similar precursor of the N250 peak was seen in the AGA group but not in the SGA group between 6 and 9 mo. The mean voltage over the 250 - to $350-\mathrm{ms}$ interval was significantly more positive in the SGA compared with the AGA infants and also in the AGA infants and the 6-mo-old control infants compared with the 9-mo-old control infants $[F(3,38)=6.10 ; P<0.0016]$. In the 250- to 350-ms latency period (the latency of the P3a), the positive difference wave voltage was larger in the AGA than in

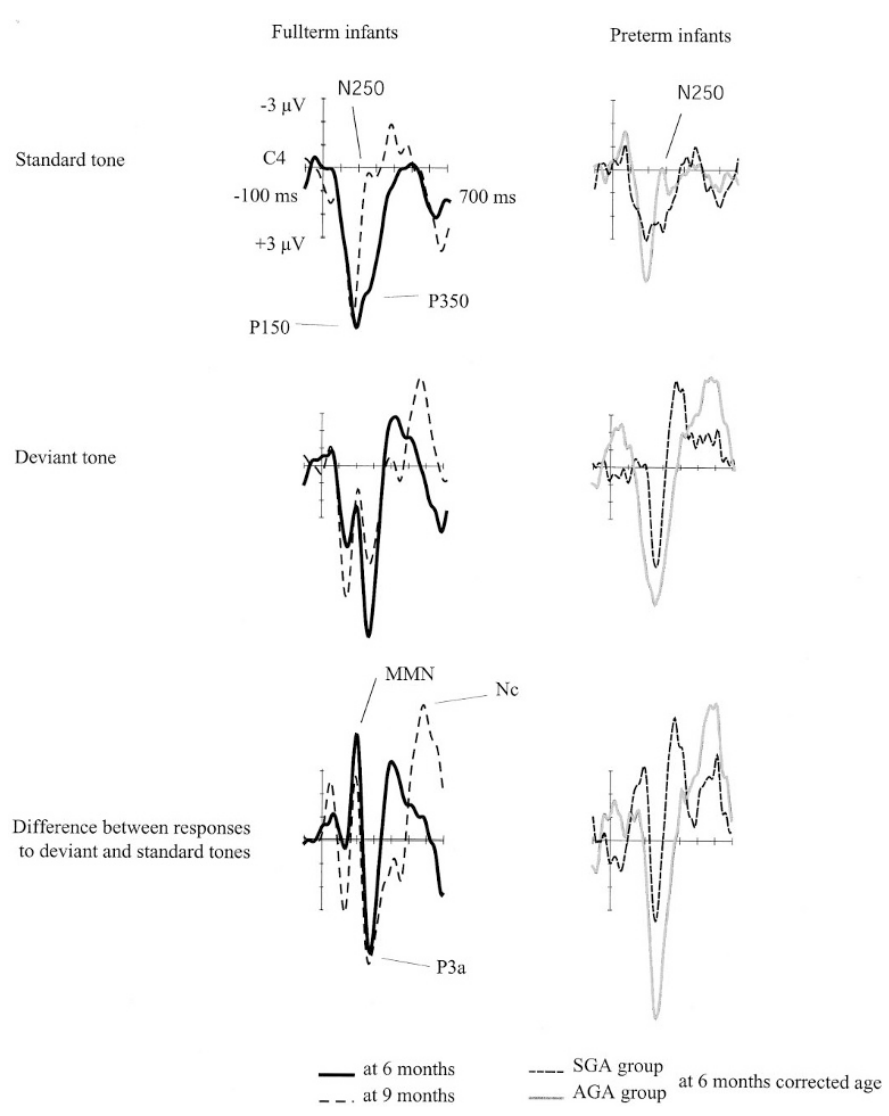

Figure 3. ERPS at the age of 6 mo corrected for prematurity in the preterm groups and in control infants at 6 mo (similar postconceptional age) and 9 mo (similar postnatal age) of age. 
the SGA and the 6-mo-old control infants but not larger than in the 9-mo-old control infants $[F(3,38)=3.64, P<0.022)$.

ERPs at 12 mo of age corrected for prematurity. In 1-y-old control infants, the mean voltage over the 150 - to $250-\mathrm{ms}$ period in response to the deviant tone was significantly more negative than that to the standard $[F(1,9)=10.31, P<0.0107$; $F(1,9)=8.21, P<0.0186$, for 12 - and 15-mo-old infants, respectively], resulting in an obvious MMN at $200 \mathrm{~ms}$ (Fig. 4). In the AGA infants, in contrast, the response to the deviant was significantly more positive than that to the standard over both the 150 - to 250 -ms $[F(1,10)=9.55 ; P<0.0114]$ and the 250 to 350 -ms periods $[F 1,10)=20.49 ; P<0.0011)$, the $\mathrm{MMN}$ thus being indistinguishable (Fig. 4). In the SGA infants, the difference between the responses to the deviant and standard was not significant. The mean voltage over the 150 - to 250 -ms period in the difference wave was significantly more positive in both preterm groups $[F(3,37)=8.59 ; P<0.0002]$ compared with that in the control infants at both ages.

Predictive value of ERPs. In the preterm infants at $40 \mathrm{wk}$ of gestational age, the positive peak to the standard stimuli at the parietal electrodes correlated with the 2-y Bayley developmental index, both over the 150 - to 250 -ms (the P150; $r=0.6, P$ $<0.048$ ) and the 250- to 350-ms (the P350; $r=0.64, P<$ 0.032 latency windows.

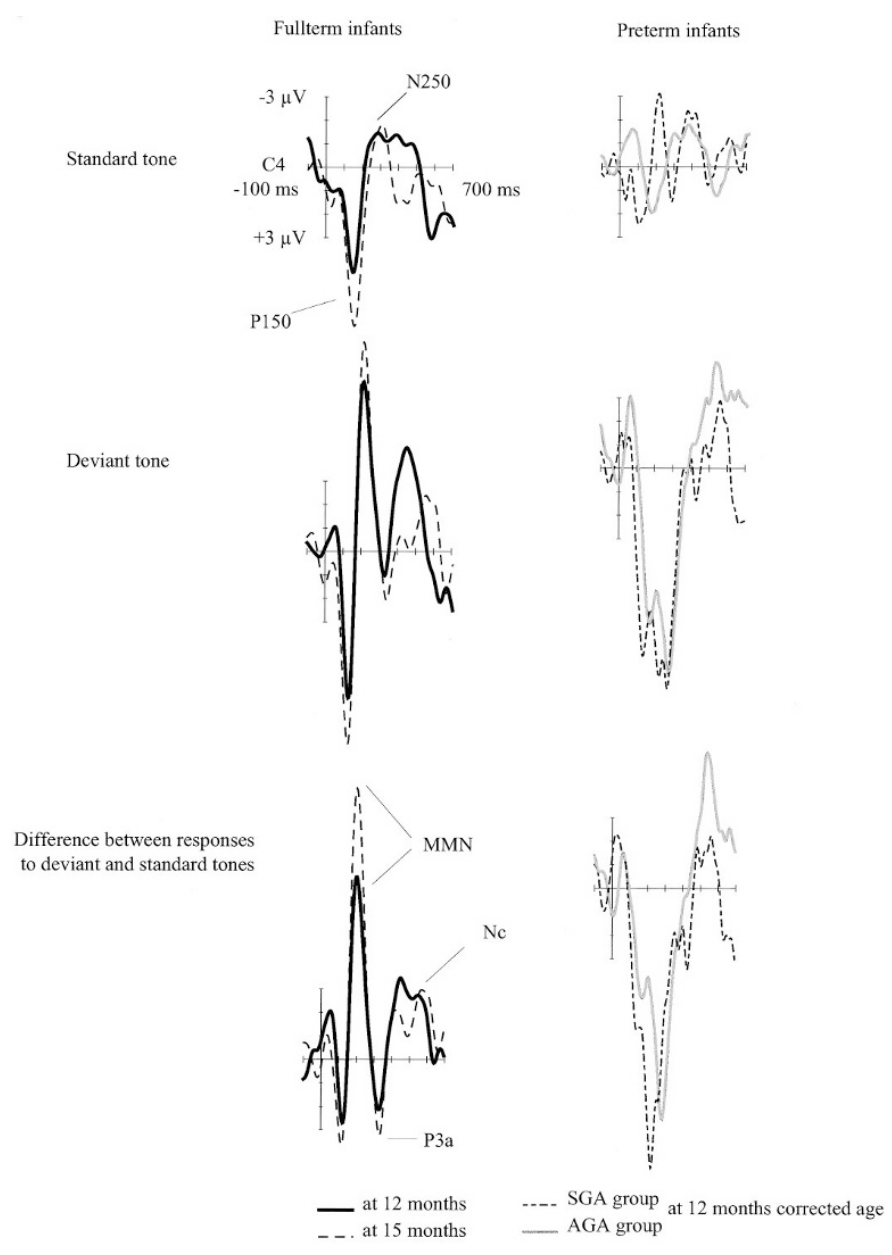

Figure 4. ERPS at the age of 12 mo corrected for prematurity in preterm infants and in control infants at 12 and 15 mo of age.
At 6 mo of corrected age, the MDI correlated positively with the mean voltage at parietal electrodes in the 50- to $150-\mathrm{ms}$ period (the P150; $r=0.87, P<0.0001$ and $r=0.63, P<$ 0.039 , for the deviant and the standard, respectively) and negatively with that of the 250 - to $350-\mathrm{ms}$ period (the N250; $r$ $=-0.63, P<0.0 .41)$ in response to the standard stimuli at the frontal electrodes. Also at 12 mo of age, the MDI correlated negatively $(r=-0.59, P<0.044)$ with the mean voltage in the 250- to $350-\mathrm{ms}$ window (the N250) at the frontal electrodes to the standard stimuli. Furthermore, the mean difference voltage in this latency window (the P3a) at the frontal $(r=0.61$, $P<0.037)$ and central $(r=0.64, P<0.025)$ electrodes was positively correlated with the MDI.

\section{DISCUSSION}

In the present study, a broad ERP positivity $(\mathrm{P} 150+\mathrm{P} 350)$ was observed in the control infants at birth; nevertheless, both the MMN and Nc could be identified. An increasing P350 peak and the development of MMN, as well as the appearance of the P3a and Nc peaks in the difference wave, characterized ERP maturation from birth to 3 mo of age. The amplitude of the early positive peak, the P150, to the standard was largest at 3 mo of age. The responses to standards and deviants were significantly different in the 50 - to 150 -ms period in 3 -mo-old infants. Between 6 and 9 mo of age, the precursor of the N250 response to the standard stimuli appeared, and the magnitude of the MMN increased. Between 12 and 15 mo of age, the N250 peak became prominent in response to both the standard and the deviant, the $\mathrm{MMN}$ was present, and the negative difference between the responses to the deviant and to the standard stimuli over 250- to 350-ms was significant. These findings are in accordance with previous studies $(13,18)$; however, the smaller N250 response at birth might be partly refracted as a result of a short interstimulus interval.

In the preterm infants at the age of 40 gestational wk, the MMN was absent and the Nc peak was smaller in the SGA than in the AGA infants. At 6 mo of age, the precursor of the N250 peak was found in the AGA but not in the SGA infants. At 12 mo of age, the response to the deviant was characterized by a broad positivity in both groups. Thus, in the preterm infants, no distinct MMN was found, but instead a broad difference positivity, peaking at the P3a latency and followed by Nc, was observed.

ERP peak amplitudes increase and peak latencies shorten with ERP maturation during infancy (19) apparently because of increasing synaptic density, efficacy, and synchronization (20). The amplitudes do not increase linearly, however. Our recent longitudinal study (13) showed that until the age of 3 mo, the amplitudes of the positive peaks increase, whereas the negative peaks start to grow only thereafter. Furthermore, we found that the precursors of all peaks observed at the age of $1 \mathrm{y}$ were identifiable already at birth at approximately the same latencies $(13,16)$. That was the case in this present study, too. By the age of $1 \mathrm{y}$, the infant ERP attained the typical morphology (P150N250-N450) found during the next 9 y of life (21).

The finding that the ERPs of the preterm infants at 40 gestational wk to standard stimuli were similar to the newborn 
but not to the 3-mo-old control infants suggests that exposure to extrauterine auditory stimulation for a mean duration of $\sim 3$ mo did not influence the maturation of auditory processing of the infants. Thus ERPs of preterm infants should be compared with control infants of a similar postconceptional rather than postnatal age.

Abnormal flash visual and somatosensory cortical evoked potentials have been observed during the first week of life in asphyxiated newborns with neurologic sequelae at $2 \mathrm{y}$ of age (22). In a study on VLBWI, an abnormal cortical visual evoked potential was found in four infants, who had an abnormal ultrasound finding postnatally and neurologic sequelae at $3 \mathrm{y}$ of age (23). In accordance with the present study, the development of the visual evoked potentials was not influenced by exposure to extrauterine life (23).

Because scalp-recorded ERPs mainly represent cortical synaptic activity, the maturational changes in electric brain responses may involve alterations in intracortical synaptic organization and synaptic density. The synaptic density of the auditory cortex reaches its maximum close to the age of 3 mo (24). At that age, we have previously found an almost 3-fold increase of the main positivity compared with the amplitude at birth (13). Early postnatal synaptic production might be a continuation of the autonomous synaptogenesis seen before birth, because synaptic density often correlates with the postconceptional age rather than postnatal experience (25). This is in accordance with our finding that the growth of the sensory positive peaks is delayed in preterm compared with full-term infants.

The response to an auditory change in infants from birth to 3 mo of age consists of the difference negativity, the MMN-like response, and the difference positivity, the P3a-like response (16), or at least of one of these $(26,27)$. In the full-term infants, we found significant differences between the responses to the deviant and standard tones, which correspond to the MMN and the P3a. In the preterm AGA infants at term, the response to the deviant was more positive than that to the standard over the earlier latency window (150-250 ms), and in the SGA group, no significant difference occurred between the standard and the deviant responses. The absence of MMN in the AGA and the SGA infants may indicate poorer sound discrimination, which occurs after peripheral sensory encoding and before conscious perception. The absence or diminished amplitude of MMN has been shown in adults and school-age children with language and reading difficulties $(28,29)$ and learning problems $(30)$. The absence of any (negative or positive) change-detection response in the SGA infants may suggest an increased risk for language or learning problems. It is interesting that the main broad peak at term in response to the deviant at the latency of MMN was positively correlated with the developmental index at $2 \mathrm{y}$ of age.

The Nc component, also associated with detection of change, was significantly smaller in the SGA than AGA and control infants. In previous studies, the $\mathrm{Nc}$ was absent in newborn high-risk infants with abnormal cortical responses (15) and in pediatric and adult patients with autism (31). The negative slow wave similar to the $\mathrm{Nc}$ was attenuated in infants of diabetic mothers and correlated with 1-y MDI (32). Thus, we suggest that the diminished amplitude of the Nc in the SGA group may indicate an increased risk for later cognitive dysfunction.

In preterm infants at the corrected age of $6 \mathrm{mo}$, as well as in 6- and 9-mo-old control infants, the major change in the ERP wave form was the emergence of the N250 peak (13). In the present study, in response to the standard tone, the N250 was present in the 9-mo-old control infants and in the AGA preterm group but diminished in the SGA group. In response to the deviant tone, both 6- and 9-mo-old control infants showed a clear N250 peak, whereas it was absent in both preterm groups. In this age period, the typical change-detection response consists of the MMN (33) or the difference positivity (the P3a) (34) or both $(16,33)$. Because the MMN and the P3a partly overlap, the MMN can be diminished (16) or even abolished (27) by the larger amplitude positive difference component, the P3a. Thus, statistically significant alterations of the MMN may not appear at the age of 6 and $9 \mathrm{mo}$. The response to the standard stimuli, however, is fairly consistent, and an absent or decreased N250 is a reliable sign of diverted central auditory processing. This assumption is based on the findings in infants with craniofacial anomalies, in whom the missing N250 was associated with an increased risk of developmental delay (35), as well as in 6- to 17-mo-old infants with plagiocephaly, in whom the N250 amplitude was significantly smaller than in their sex- and age-matched control subject (36). Furthermore, the N250 was diminished in school-age dysphasic (33) and language-impaired children (37). The correlation in the present study between the N250 peak and the developmental index suggests that this ERP component may be of value as a measure of cognition.

At $1 \mathrm{y}$ of age, both AGA and SGA infants showed a positivity in response to the deviant and positive-voltage difference waves. Although the difference waves in AGA and SGA groups look very similar, there were no significant differences between the responses to standard and deviant in the SGA group, whereas in AGA group, the response to deviant was significantly different from that to standard. This suggests that although in the AGA group auditory change consistently elicited the enhanced positivity, in the SGA group, the individual waveforms were much more variable, indicating higher diversity of brain response to change in these infants. The positive voltage of the difference wave may reflect a delayed ERP maturation in preterm infants, as a similar positivity has been found in some full-term infants at 6 mo of age (16). Because the difference voltage over the time periods at the P3a latency correlated with the MDI 1 y later, the P3a may have a predictive value for the outcome.

Because the frequency deviation between the deviant and standard stimuli in the present study was relatively large, the response to the deviant stimulus may reflect a stronger CNS arousal in preterm than full-term infants. Similar results were obtained by Alho et al. (34), who found a greater positive voltage (presumably P3a) in 4- to 7-mo-old prematurely born infants than in age-matched control subjects in response to tone change. This finding might be associated with increased distractibility, because an enhanced P3a response has previously 
been reported in children (38) and adult patients (39) with increased distractibility.

In conclusion, the main findings in our study were consistent ERP differences between the preterm infants and full-term healthy infants during the first year of life and a correlation between the ERPs and the developmental index at $2 \mathrm{y}$ of age. This may suggest an increased risk of cognitive dysfunction in prematurely born children. In an earlier VLBWI study (40), the Bayley assessment at $1 \mathrm{y}$ of age correlated with the test results of cognitive performance at $5 \mathrm{y}$ of age. In infants at risk for language disorders, abnormal cortical ERPs in the neonatal period were associated with later deficiencies in languageprocessing skills (41). For testing the hypothesis that an abnormal ERP during the first year of life in preterm infants indicates later cognitive dysfunction, follow-up needs to be extended to preschool age, when detailed neuropsychologic testing is possible.

Acknowledgment. We thank Tarja Ilkka for collecting the ERP data.

\section{REFERENCES}

1. Tin W, Wariyar U, Hey E 1997 Changing prognosis for babies of less than 28 weeks' gestation in the north of England between 1983 and 1994. Northern Neonatal Network. BMJ 314:107-111

2. Darlow BA, Cust AE, Donoghue DA, Australian and New Zealand Neonatal Network 2003 Improved outcomes for very low birth weight infants: evidence from New Zealand national population based data. Arch Dis Child Fetal Neonatal Ed 88:F23F28

3. Tommiska V, Heinonen K, Kero P, Pokela ML, Tammela O, Järvenpää AL, Salokorpi T, Virtanen M, Fellman V 2003 A national 2 year follow up study of extremely low birth weight infants born in 1996-1997. Arch Dis Child Fetal Neonatal Ed 88:F29F35

4. Doyle LW, Victorian Infant Collaborative Study Group 2001 Outcome at 5 years of age of children 23 to 27 weeks gestation, refining the prognosis. Pediatrics 108:134 141

5. Hille ET, den Ouden AL, Bauer L, van den Oudenrijn C, Brand R, VerlooveVanhorick SP 1994 School performance at nine years of age in very premature and very low birth weight infants: perinatal risk factors and predictors at five years of age. Collaborative Project on Preterm and Small for Gestational Age (POPS) Infants in The Netherlands. J Pediatr 125:426-434

6. Saigal S, Hoult LA, Streiner DL, Stoskopf BL, Rosenbaum PL 2000 School difficulties at adolescence in a regional cohort of children who were extremely low birth weight. Pediatrics 105:325-331

7. Bylund B, Cervin T, Finnstrom O, Gaddlin PO, Leijon I, Mard S, Samuelsson S Sandstedt P, Warngard O 2000 Very low birth weight children at 9 years: school performance and behavior in relation to risk factors. Perinat Neonatal Med 5:124-133

8. Leipälä J, Greenough A 2002 The short and long term effects of intrauterine growth retardation. Contemp Clin Gynecol Obstet 2:161-167

9. Korkman M, Liikanen A, Fellman V 1996 Neuropsychological consequences of very low birth weight and asphyxia at term - a follow-up until school-age. J Clin Exp Neuropsychol 18:220-233

10. Näätänen R 1992 Attention and Brain Function. Lawrence Erlbaum, Hillsdale, pp 102-200

11. Cheour M, Leppanen PH, Kraus N 2000 Mismatch negativity (MMN) as a tool for investigating auditory discrimination and sensory memory in infants and children. Clin Neurophysiol 111:4-16

12. Stapells DR, Kurtzberg D 1991 Evoked potential assessment of auditory system integrity in infants. Clin Perinatol 18:497-518

13. Kushnerenko E, Ceponiene R, Balan P, Fellman V, Huotilainen M, Näätänen R 2002 Maturation of the auditory event-related potentials during the first year of life. Neuroreport 13:47-51

14. Näätänen R, Gaillard AW, Mäntysalo S 1978 Early selective attention effect on evoked potential reinterpreted. Acta Psychol 42:313-329
15. Kurtzberg D, Vaughan HG, Novak GP 1986 Discriminative brain responses to speech sounds in the newborn high risk infant. In: Gallai V (ed) Maturation of the CNS and Evoked Potentials. Elsevier, Amsterdam, pp 253-259

16. Kushnerenko E, Ceponiene R, Balan P, Fellman V, Näätänen R 2002 Maturation of the auditory change-detection response in infants: a longitudinal ERP study. Neuroreport 13:1843-1848

17. Ceponiene R, Kushnerenko E, Fellman V, Renlund M, Suominen K, Näätänen R 2002 Event-related potential features indexing central auditory discrimination by newborns. Brain Res Cogn Brain Res 13:101-113

18. Novak GP, Kurtzberg D, Kreuzer JA, Vaughan HG Jr 1989 Cortical responses to speech sounds and their formants in normal infants: maturational sequence and spatiotemporal analysis. Electroencephalogr Clin Neurophysiol 73:295-305

19. Thomas DG, Crow CD 1994 Development of evoked electrical brain activity in infancy. In: Dawson G, Fisher KW (eds) Human Behavior and the Developing Brain. The Guilford Press, New York, pp 207-231

20. Vaughan HG Jr, Kurtzberg D 1992 Electrophysiologic indices of human brain maturation and cognitive development. In: Gunnar MR, Nelson CA (eds) Minnesota Symposia on Child Psychology. Erlbaum, Hillsdale, pp 1-36

21. Ceponiene R, Rinne T, Näätänen R 2002 Maturation of cortical sound processing as indexed by event-related potentials. Clin Neurophysiol 113:870-882

22. Scalais E, Francois-Adant A, Nuttin C, Bachy A, Guerit JM 1998 Multimodality evoked potentials as a prognostic tool in term asphyxiated newborns. Electroencephalogr Clin Neurophysiol 108:199-207

23. Atkinson J, Anker S, Rae S, Weeks F, Braddick O, Rennie J 2002 Cortical visual evoked potentials in very low birthweight premature infants. Arch Dis Child Fetal Neonatal Ed 86:F28-F31

24. Huttenlocher PR, Dabholkar AS 1997 Regional differences in synaptogenesis in human cerebral cortex. J Comp Neurol 387:167-178

25. Zecevic N, Rakic P 1991 Synaptogenesis in monkey somatosensory cortex. Cereb Cortex 1:510-523

26. Dehaene-Lambertz G, Dehaene S 1994 Speed and cerebral correlates of syllable discrimination in infants. Nature 28:293-294

27. Morr ML, Shafer VL, Kreuzer JA, Kurtzberg D 2002 Maturation of mismatch negativity in typically developing infants and preschool children. Ear Hear 23:118 136

28. Korpilahti P, Lang HA 1994 Auditory ERP components and mismatch negativity in dysphasic children. Electroencephalogr Clin Neurophysiol 91:256-264

29. Baldeweg T, Richardson A, Watkins S, Foale C, Gruzelier J 1999 Impaired auditory frequency discrimination in dyslexia detected with mismatch evoked potentials. Ann Neurol 45:495-503

30. Kraus N, McGee T, Carrell TD, Zecker SG, Nicol TG, Koch DB 1996 Auditory neurophysiologic responses and discrimination deficits in children with learning problems. Science 273:971-973

31. Courchesne E 1990 Chronology of postnatal human brain development: event-related potential, positron emission tomography, myelinogenesis, and synaptogenesis studies, event-related brain potentials. In: Rohrbaugh R, Parasuraman R, Johnson R (eds) Basic Issue and Applications. Oxford University Press, New York, pp 210-241

32. DeRegnier RA, Nelson CA, Thomas KM, Wewerka S, Georgieff MK 2000 Neurophysiologic evaluation of auditory recognition memory in healthy newborn infants and infants of diabetic mothers. J Pediatr 137:777-784

33. Trainor LJ, Samuel SS, Desjardins RN, Sonnadara RR 2001 Measuring temporal resolution in infants using mismatch negativity. Neuroreport 12:2443-2448

34. Alho K, Sajaniemi N, Niittyvuopio T, Sainio K, Näätänen R 1990 ERPs to an auditory stimulus change in preterm and full-term infants. In: Brunia CHM, Gaillard AWK, Kok A (eds) Psychophysiological Brain Research. Tilburg University Press, Tilburg, pp 139-142

35. Ceponiene R, Haapanen ML, Ranta R, Näätänen R, Hukki J 2002 Auditory sensory impairment in children with oral clefts as indexed by auditory event-related potentials. J Craniofac Surg 13:544-566

36. Balan P, Kushnerenko E, Sahlin P, Huotilainen M, Näätänen R, Hukki J 2002 Auditory ERPs reveal brain dysfunction in infants with plagiocephaly. J Craniofac Surg 13:520-525

37. Tonnquist-Uhlen I 1996 Topography of auditory evoked long-latency potentials in children with severe language impairment: the P2 and N2 components. Ear Hear $17: 314-326$

38. Kilpeläinen R, Luoma L, Herrgard E, Yppärila H, Partanen J, Karhu J 1999 Persistent frontal P300 brain potential suggests abnormal processing of auditory information in distractible children. Neuroreport 10:3405-3410

39. Kaipio ML, Cheour M, Ceponiene R, Öhman J, Alku P, Näätänen R 2000 Increased distractibility in closed head injury as revealed by event-related potentials. Neuroreport 11:1463-1468

40. Vohr B, Garcia Coll C, Flanagan P, Oh W 1992 Effects of intraventricular hemorrhage and socioeconomic status on perceptual, cognitive, and neurologic status of low birth weight infants at 5 years of age. J Pediatr 121:280-285

41. Molfese DL 2000 Predicting dyslexia at 8 years of age using neonatal brain responses. Brain Lang 72:238-245 